\title{
Optimization of Removal of Cadmium (II) using Response Surface Methodology
}

\author{
Sateesh Hosamane $^{1, *}$, Sneha Bandekar', Chidanand Patil ${ }^{2}$ and Keshava Joshi ${ }^{3}$ \\ ${ }^{I}$ Department of Chemical Engineering, KLE DR M S Sheshgiri College of Engineering and Technology, \\ Belagavi, Karnataka 590008, India \\ ${ }^{2}$ Department of Civil Engineering, KLE DR M S Sheshgiri College of Engineering and Technology, \\ Belagavi, Karnataka 590008, India \\ ${ }^{3}$ Department of Chemical Engineering, SDM College of Engineering and Technology, Dharwad, \\ Karnataka 590008, India
}

('Corresponding author's e-mail: satishosamane@gmail.com)

Received: 15 October 2020, Revised: 5 April 2021, Accepted: 15 April 2021

\begin{abstract}
A huge quantity of wastewater is generated and dumped directly into the natural environment. Industrial wastewater recycling is common in India and is mainly used for agriculture in the surrounding areas. This has led to high levels of cadmium and other heavy metals in the air, water, and soil. Natural adsorbents provide an effective solution for wastewater treatment. Wooden objects can be used to remove heavy metals from contaminated water. The current investigation attempts to remove cadmium from the cadmium-containing aqueous solution using the root of Calotropis Procera. The adsorption process was developed with batch studies to quantify the removal of cadmium (Y) using 3 flexible process variables namely, $\mathrm{pH}$, residence time $(\mathrm{CT})$, and adsorbent dose (AD). Interaction between variables, a $20\left(2^{3}\right)$ central composite design (CCD) was developed using the response surface method (RSM). The results of the adsorption verification tests were performed and show excellent compliance with the model prediction. The value of $\mathrm{F}(550.78)$ and the return coefficient $\left(\mathrm{R}^{2}\right)$ of 0.9796 proved the validity of the improved quadratic model.
\end{abstract}

Keywords: Cd (II), Calotropis procera, Adsorption, RSM

\section{Introduction}

Uncontrolled industrialization is one of the reasons for environmental pollution, and the removal of pollutants from wastewater is a serious issue. Regular disposal of various pollutants such as heavy metals, organic solvents, and chemicals into the natural environment is a growing issue worldwide [1]. India produces about 13,500 - 15,000 million litres of industrial wastewater per day and directly discharged without appropriate treatment due to the high cost of treatment. Wastewater comprising toxic and heavy metals falling into the nearby river, a source of drinking water for the town's downstream [2]. The presence of these pollutants will cause changes in the chemical, physical, and biological systems of the aquatic environment and can damage living organisms [3]. A study by the department of water resources revealed that the water in the river and the banks are contaminated with high concentrations of these metals which exceed the Bureau of Indian Standard (BIS) water and drinking water quality [4]. Heavy metals are a serious environmental concern of national and international environmental legislation because they are deadly even at low concentrations, bioaccumulation, and possible food contamination. As per the World Health Organization (WHO), cadmium (Cd-II) is a neuro-toxic substance, which gets easily introduced, assimilated into the food chain/natural habitat, and is responsible for severe health problems [5]. Several studies reported that Cadmium pollution in a city environment is widespread [6]. Cadmium is released into receiving water areas from, fertilizers (phosphate), cadmium-nickel batteries, pesticides, petroleum, plastic processing, dyes, welding, metal production (iron and steel), photography, and electroplating industries [7]. Cd (II) is highly toxic and has a carcinogenic effect on humans and animals [8]. The allowable limits of cadmium in drinking water are $0.003 \mathrm{mg} / \mathrm{L}$. Based on the source of these harmful health effects, Cd (II) was marked as a red list substance in the 
year 1991 by the department of environment, UK [9]. Excessive toxicity in very low doses will cause kidney damage, kidney disorders [10], increase blood pressure [11], damage to bone marrow [12], and reduction in red blood cell generation [13]. The allowable Cd (II) limit as defined by WHO, is $0.01 \mathrm{mg} / \mathrm{L}$. Food is the main cause of cadmium contamination in individuals. Plants have the capacity to hyper accumulate cadmium, leafy vegetables comprise about $0.05-0.12 \mathrm{mg}$ cadmium $/ \mathrm{kg}[14,15]$. Large extensive methods such as precipitation and co-precipitation [16], ion exchange [17], and adsorption [18], cementation [19], membrane separation [20], etc. have been established for cadmium removal for recycling and reuse of wastewater [21,22]. In recent years, various studies have revealed the necessity of developing affordable and eco-friendly adsorbents. The agricultural waste and biomass from the environment can be used as an adsorbent; these bioadsorbents contain various functional groups, such as hydroxyls and amines, which have a high affinity for the metal complexes. After the adsorption process, the adsorbed heavy metals can be recovered using acid or base treatments, and then the bio-adsorbents can be reused. This will generate additional industrial capital. Studies have been conducted on Calotropis Procera to treat wastewater with heavy metals. Calotropis Procera is a flowering-bearing species belonging to the family Apocynaceae originating in Africa, Asia, and Indochina. Shrub Calotropis Procera biomass was selected for adsorption study due to its presence in Karnataka. The roots of Calotropis Procera native in the presence of $\mathrm{O}-\mathrm{H}, \mathrm{C}=\mathrm{O}, \mathrm{C}-\mathrm{N}, \mathrm{C}-\mathrm{H}, \mathrm{NH}_{2}, \mathrm{C}-\mathrm{O}, \mathrm{COOH}$, and $\mathrm{POH}$ as functional groups. The multiplicity of functional groups designates the composite characteristics of the biomass studied. The same was reported in the previous studies on functional groups of Calotropis Procera a biomass [23,24]. The RSM was used in this study to understand the effects associated with process parameters, enabling them to perform with a concise and precise set of experiments. The use of a multivariate research program is an appealing and popular approach to engineering and scientific research. The RSM process is a combination of a statistical and mathematical tool used to design the experiments (DOE) with the help of mathematical models. The method is used to quantify the important interactions with their results and determine the optimal condition for the correct result [25]. The advanced RSM and Central Composite Design (CCD) have been employed for the DOE [26]. Twenty-three-point study design with 4 axial points and 6 replicates in 20 test trials is used to optimize the adsorption process [27]. The present study aims to investigate the possibility of Calotropis Procera biomass to remove cadmium (II) ion from aqueous solution by optimizing the process using $\mathrm{pH}(\mathrm{A}), \mathrm{CT}(\mathrm{B})$, and $\mathrm{AD}(\mathrm{C})$.

\section{Materials and methods}

\section{Preparation of adsorbent}

The roots of the plant were collected, washed with tap water for $10 \mathrm{~min}$ followed by rinsing with deionized water to remove dust and sand particles. The plant roots were dried in an oven at $60{ }^{\circ} \mathrm{C}$ for $2 \mathrm{~h}$, cooled, and stored in a desiccator. The final biomass was powdered and sieved to maintain $\leq 200 \mu \mathrm{m}$ sizes.

\section{Preparations of chemicals and experiments}

A Stock solution of $1,000 \mathrm{mg} / \mathrm{L}$ was prepared by dissolving $2.74 \mathrm{~g}$ of cadmium nitrate $\left[\mathrm{Cd}\left(\mathrm{NO}_{3}\right)_{2} \cdot 4 \mathrm{H}_{2} \mathrm{O}\right]$ in one liter of distilled water. The samples 5 to $100 \mathrm{ppm}$ concentrations were prepared by diluting stock solution. The $\mathrm{pH}$ of the stock solution was adjusted using 0.1 M HCL and $0.1 \mathrm{M} \mathrm{NaOH}$ as per experimentation requirement. Absorption measurements were made with an atomic absorption spectrometer, which included a blank cathode lamp for cadmium and a deuterium lamp for background correction with the following settings; wavelength - $228.8 \mathrm{Nm}$, Split width - 0.7, Lamp current - $8 \mathrm{~mA}$, using air/acetylene flame. The statistical software (Design expert 8.0.7.1) was used for the experimental design and central composite design (CCD) was adopted for the optimization of adsorption experiments. The experimental design consists of 3 variables viz. $\mathrm{pH}$, Residence time, and adsorbent dose [28].

\section{Preparations of chemicals and experiments}

A Stock solution of $1,000 \mathrm{mg} / \mathrm{L}$ was prepared by dissolving $2.74 \mathrm{~g}$ of cadmium nitrate $\left[\mathrm{Cd}\left(\mathrm{NO}_{3}\right)_{2} \cdot 4 \mathrm{H}_{2} \mathrm{O}\right]$ in one liter of distilled water. The samples 5 to $100 \mathrm{ppm}$ concentrations were prepared by diluting stock solution. The $\mathrm{pH}$ of the stock solution was adjusted using $0.1 \mathrm{M} \mathrm{HCL}$ and $0.1 \mathrm{M} \mathrm{NaOH}$ as per experimentation requirement. Absorption measurements were made with an atomic absorption spectrometer, which included a blank cathode lamp for cadmium and a deuterium lamp for 
background correction with the following settings; wavelength - $228.8 \mathrm{Nm}$, Split width - 0.7, Lamp current - $8 \mathrm{~mA}$, using air/acetylene flame. The statistical software (Design expert 8.0.7.1) was used for the experimental design and central composite design (CCD) was adopted for the optimization of adsorption experiments. The experimental design consists of 3 variables viz. $\mathrm{pH}$, Residence time, and adsorbent dose [28].

\section{Batch experiments}

The batch experiments are planned with a cadmium solution to calculate the $\mathrm{Cd}$ (II) removal. To investigate the effects of the specified parameters, the experiments were performed using 3 process parameters with a varied range. The parameters involved are the $\mathrm{pH}$ of the sample $(1-6)$, the adsorbent dose $(0.5-2.5 \mathrm{~g})$, and the residence time $(20-100 \mathrm{~min})$ by maintaining the initial Cd (II) ion concentration at $60 \mathrm{mg} / \mathrm{L}$ and mixing speed of agitation at 120 RPM. Calibration curves are constructed by planning the values of absorption and concentration using atomic absorption spectrophotometer. The percent removal (Y \%) of Cd ion by adsorption was calculated using Eq. (1);

$Y \%=\frac{C i-C o}{C i} X 100$

Where, $Y \%$ is percentage removal of $\mathrm{Cd}$ (II), $C_{i}$ initial concentration of the Cd (II) sample, $C_{i=}$ final concentration of the Cd (II) sample.

\section{Design of experiments (DOE)}

To optimize the process, 3 variables are selected to test the adsorption efficiency on cadmium removal using 3-level CCD. The range of parameters used for the experiment is shown in Table 1. Twenty experiments $\left(2^{3}\right)$ with different runs of trials that were generated by the software are used to determine the maximum $\mathrm{Cd}$ (II) removal referred to as response or output (Y).

Table 1 Range of variables used for the experimental design.

\begin{tabular}{lcccc}
\hline & & \multicolumn{2}{c}{ Level } \\
\hline Factors & Symbol & $\mathbf{1}$ & $\mathbf{0}$ & $\mathbf{1}$ \\
\hline $\mathrm{pH}$ & $\mathrm{A}$ & 1 & 3.5 & 6 \\
Residence time (CT), min & $\mathrm{B}$ & 20 & 60 & 100 \\
Adsorbent Dosage (AD), g & $\mathrm{C}$ & 0.5 & 1.5 & 2.5 \\
\hline
\end{tabular}

RSM is a progressive approach to optimize the process parameters by following steps; i) designing of experiments, ii) scrutinize the outcomes with the help of model prediction, and iii) conclude the optimum conditions for the process [29-31]. RSM expresses the relationship between different input factors and the output or response as:

$Y=f\left(x_{1}, x_{2}, x_{3}, \ldots . x_{n}\right)$

Where $\mathrm{Y}$ is the response or removal or output;

$x_{1}, x_{2}, x_{3}, \ldots x_{n}$ is separate independent entities of the processes.

CCD is a unique, very popular, and powerful technique for a second-order design that has been employed in the current investigation. The total amount of combination required to perform optimization of the process is given by;

$N=2^{k}+2 k+n_{0}$

Where ' $k$ ', ' $n_{o}$ ' represents the number of independent variables and number of test duplicates respectively in the centre point with 3 inputs for investigation.

$N=2^{3}+(2 \times 3)+6$

The complete design in CCD consisted of 3 components ( $\mathrm{pH}-\mathrm{A}, \mathrm{CT}-\mathrm{B}, \mathrm{AD}-\mathrm{C}$ ), each of the 3 levels $(-1,0,+1)$ shown in Table 2 . The association between the coded and un-coded (actual) standards is described using the Eq. (5). 
$X_{i}=\frac{x_{i}-x_{0 i}}{\Delta x_{i}}$

where $\mathrm{X}_{i}$ is the coded value, $\mathrm{x}_{i}$ is the corresponding independent variable value, $\mathrm{x}_{0 i}$ is the independent variable actual value at the center point, and $\Delta \mathrm{x}_{i o}$ is the change (step) in the process.

The experimental data are statistically analysed using the response surface regression technique. The correlation between output (response) and input (independent) is obtained by using the second polynomial equation:

$$
Y=\alpha_{0}+\sum_{i=1}^{k} \alpha_{i} x_{i}+\sum_{i=1}^{k} \alpha_{i i} x_{i}^{2}+\sum \sum_{i<j}^{k} \alpha_{i j} x_{i} x_{j}+\varepsilon
$$

where $\mathrm{Y}$ is the output, $\alpha_{0}$ is the constant, $\alpha_{i}$ is the trend or the direct effect of the xi data, $\alpha_{i i}$ is the quadratic result of factor $\mathrm{x}_{i}, \alpha_{i j}$ is a line of contact between the input element of $\mathrm{xi}$, and $\varepsilon$ is a residual word.

\section{Results and discussion}

\section{Adsorption study and process optimization}

Adsorption capacity and removal percentages of Cd (II) are presented in Table 2. The adsorbent showed great attraction for $\mathrm{Cd}$ (II), the response or removal was calculated using multiple regression study, the regression constants of the adsorption model were determined using 3 process parameters. After applying the multiple regression techniques, the second-order polynomial equation was investigated for percentage cadmium removal $(\mathrm{Y})$ results shown in Table 2. Eq. (7) provides the result of the experiment $(\mathrm{Y})$ in terms of process parameters.

Table 2 Experimental design of process parameters and responses for $\mathrm{Cd}$ (II) adsorption.

\begin{tabular}{llllllll}
\hline \multicolumn{2}{c}{ Coded Values } & \multicolumn{5}{c}{ Uncoded Values } \\
\hline $\mathbf{A}$ & $\mathbf{B}$ & $\mathbf{C}$ & $\mathbf{p H}(\mathbf{A})$ & $\mathbf{C T}(\mathbf{B})$ & $\mathbf{A D}(\mathbf{C})$ & $\mathbf{\% Y}$, Actual & $\mathbf{\% Y}$, \\
\hline-0.7 & 0 & 0 & -0.7 & 60.00 & 1.5 & 10.21 & 10.38 \\
0 & 0 & 0 & 3.5 & 60.00 & 1.50 & 87.26 & 84.68 \\
1 & -1 & 1 & 6.0 & 20.00 & 2.50 & 56.83 & 55.2 \\
0 & 0 & 0 & 3.5 & 60.00 & 1.50 & 84.56 & 84.68 \\
-1 & 1 & 1 & 1.0 & 100.00 & 2.50 & 57.62 & 58.67 \\
0 & 0 & 0 & 3.5 & 60.00 & 1.50 & 83.91 & 84.68 \\
7.7 & 0 & 0 & 7.7 & 60.00 & 1.50 & 42.38 & 43.77 \\
0 & -7.27 & 0 & 3.5 & -7.27 & 1.50 & 29.19 & 32.54 \\
-1 & 1 & -1 & 1.0 & 100.00 & 0.50 & 23.24 & 23.76 \\
0 & 0 & 0 & 3.5 & 60.00 & 1.50 & 84.79 & 84.68 \\
0 & 0 & 0 & 3.5 & 60.00 & 1.50 & 84.21 & 84.68 \\
1 & 1 & -1 & 6.0 & 100.00 & 0.50 & 37.97 & 36.91 \\
1 & 1 & 1 & 6.0 & 100.00 & 2.50 & 90.11 & 91.73 \\
0 & 0 & -0.18 & 3.5 & 60.00 & -0.18 & 14.91 & 17.60 \\
-1 & -1 & 1 & 1.0 & 20.00 & 2.50 & 28.64 & 28.60 \\
0 & 127.27 & 0 & 3.5 & 127.27 & 1.50 & 76.21 & 74.41 \\
0 & 0 & 0 & 3.18 & 60.00 & 3.18 & 79.98 & 78.85 \\
1 & -1 & -1 & 6.0 & 20.00 & 0.50 & 19.34 & 17.19 \\
0 & -1 & 6.36 & 1.0 & 20.00 & 0.50 & 13.21 & 10.49 \\
1 & 0 & 0 & 3.5 & 60.00 & 1.50 & 83.65 & 84.68 \\
\hline
\end{tabular}


$\% Y=-45.787+22.85 * \mathbf{p H}+0.925 * \mathrm{CT}+43.674 * \mathrm{AD}+0.016 * \mathrm{pH} * \mathrm{CT}+1.991 *$ $\mathbf{p H} * \mathrm{AD}+0.105 * \mathbf{C T} * \mathrm{AD}-3.361 * \mathbf{p H} * \mathbf{p H}-\mathbf{0 . 0 0 7} * \mathrm{CT} * \mathrm{CT}-12.90 * \mathrm{AD} * \mathrm{AD}$

Where, $\% \mathrm{Y}$ is the percentage removal of $\mathrm{Cd}(\mathrm{II}), \mathrm{pH}, \mathrm{CT}$, and $\mathrm{AD}$ are the independent variables in the process. The analysis of variance (ANOVA) is computed to support the process is shown in Table 3. The interpretation of the constant in the model is governed by $\mathrm{F}$ and $\mathrm{P}$ calculations. ANOVA is the most consistent way to evaluate the features of the constructed model. ANOVA helps to estimate the model response from the interaction between independent variables. Larger $\mathrm{f}$ and smaller $p$-values specify the consistent outcome. Linear, quadratic dimension and their relation can be proved in the above Eq. (7). The value of $\mathrm{p}$ (small) and f (large) designate an important outcome of the analogous coefficients [32].

Results in Table 3 revealed that the removal of Cd (II) was statistically significant as the value of $p$ $<0.001$ had f-values of 550.78. It is established from the regression analysis that the selected structure of the process is important for the adsorption of Cd (II). Therefore, a quadratic model is used to describe the process. The summary of the model is shown in Table 3. The probability i.e., $p<0.005$ specify the selected term in model estimation is significant. In the above calculation, the model terms $\mathrm{A}, \mathrm{B}, \mathrm{C}, \mathrm{AC}$, $\mathrm{BC}, \mathrm{A}^{2}, \mathrm{~B}^{2}, \mathrm{C}^{2}$ are significant. If $p<0.005$ specifies the insignificant term in the model. Model fit can be determined by deficiency or lack of fit term to have an f-value of 43.87 represents significance, indicating that the model is well suited for the Cd (II) adsorption process. Thus, in this study, the mean value of $\mathrm{f}$ (550.78) was determined by the ANOVA; suggests that the quadratic polynomial equation is statistically significant as shown in Table 3 and Table 4. Model specification is measured by signal-to-noise level (Adeq precision) and should be greater than 4 , the value 43.87 records the acceptable index calculated in Table 4. Therefore, the model selected in the present study is well accepted for the clear relationship between process flexibility and percentage removal of Cd (II).

Table 3 Model summary of Cd (II) removal.

\begin{tabular}{lllllll}
\hline \multicolumn{1}{c}{ Source } & \multicolumn{1}{c}{ SS } & df & \multicolumn{1}{c}{ MS } & \multicolumn{1}{c}{ f-Value } & \multicolumn{1}{c}{$\boldsymbol{p}$-value } & \\
\hline Mean & $5,9211.14$ & 1 & $59,211.14$ & & & \\
Linear & $7,998.68$ & 3 & $2,666.23$ & 4.70 & 0.0154 & \\
2FI & 360.13 & 3 & 120.04 & 0.18 & 0.9087 & Suggested \\
Quadratic & $\mathbf{8 , 6 6 0 . 7 9}$ & $\mathbf{3}$ & $\mathbf{2 , 8 8 6 . 9 3}$ & $\mathbf{5 5 0 . 7 8}$ & $<\mathbf{0 . 0 0 0 1}$ & \\
Cubic & 38.42 & 4 & 9.61 & 4.12 & 0.0609 & \\
Residual & 13.99 & 6 & 2.33 & & & \\
Total & $76,283.15$ & 20 & 3814 & & & \\
\hline
\end{tabular}

Table 4 ANOVA result of predictive model.

\begin{tabular}{llllllll}
\hline Component & SS & df & MS & f-value & t value & $\boldsymbol{p}$-value & \\
\hline Model & $1,7019.60$ & 9 & $1,891.07$ & 360.78 & 88.89 & $<0.0001$ & significant \\
A-pH & $1,347.24$ & 1 & $1,347.24$ & 257.03 & 15.91 & $<0.0001$ & \\
B-CT & $2,116.10$ & 1 & $2,116.10$ & 403.72 & 19.94 & $<0.0001$ & \\
C-AD & $4,535.33$ & 1 & $4,535.33$ & 865.27 & 29.19 & $<0.0001$ & \\
AB & 20.80 & 1 & 20.80 & 3.97 & -33.53 & $<0.0744$ & \\
AC & 198.20 & 1 & 198.20 & 37.81 & -18.15 & $<0.0001$ & \\
BC & 141.12 & 1 & 141.12 & 26.92 & -21.22 & $<0.0004$ & \\
A $^{2}$ & $5,988.12$ & 1 & $5,988.12$ & $1,142.44$ & 1.98 & $<0.0001$ & \\
B $^{2}$ & $1,759.22$ & 1 & $1,759.22$ & 335.63 & 6.10 & $<0.0001$ & \\
C $^{2}$ & $2,400.62$ & 1 & $2,400.62$ & 458.00 & 5.15 & $<0.0001$ & \\
Residual & 52.42 & 10 & 5.24 & & & & Significant \\
Lack of Fit & $\mathbf{4 3 . 8 7}$ & $\mathbf{5}$ & $\mathbf{8 . 7 7}$ & $\mathbf{5 . 1 4}$ & & $\mathbf{0 . 0 4 8 4}$ & \\
Pure Error & 8.54 & 5 & 1.71 & & & & \\
Cor Total & $17,072.01$ & 19 & & & & & \\
\hline
\end{tabular}


Figure 1 represents the normal probability plot that is straight line if the points come from a normal distribution. The experimental $(\% \mathrm{Y})$ and the predicted $(\% \mathrm{Y})$ means adjusting values measured on different scales to a notionally common scale, it was observed that the expected output value (\%Y) from the model equation was consistent with the experimental values on selected independent variables with the best value of the coefficient of determination $\left(R^{2}\right)$ [33]. The predicted and observed values imply that the use of CCD is a reliable and efficient way to calculate the adsorption efficiency and to optimize the parameters of the adsorption process.

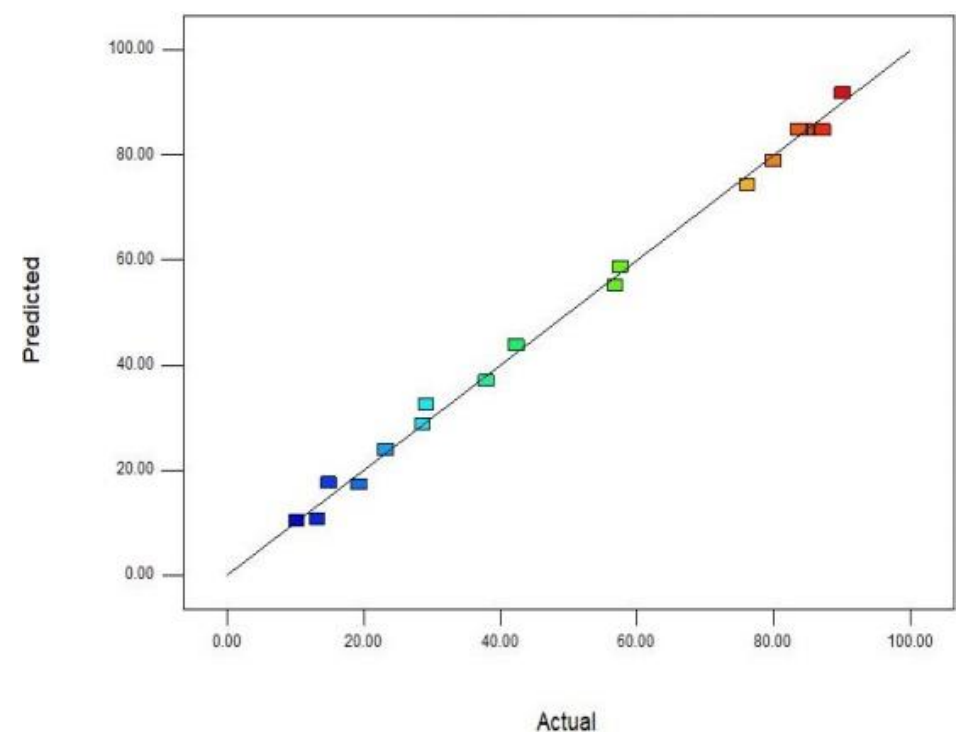

Figure 1 Normal probability plot of the DOE for Cd(II) removal.
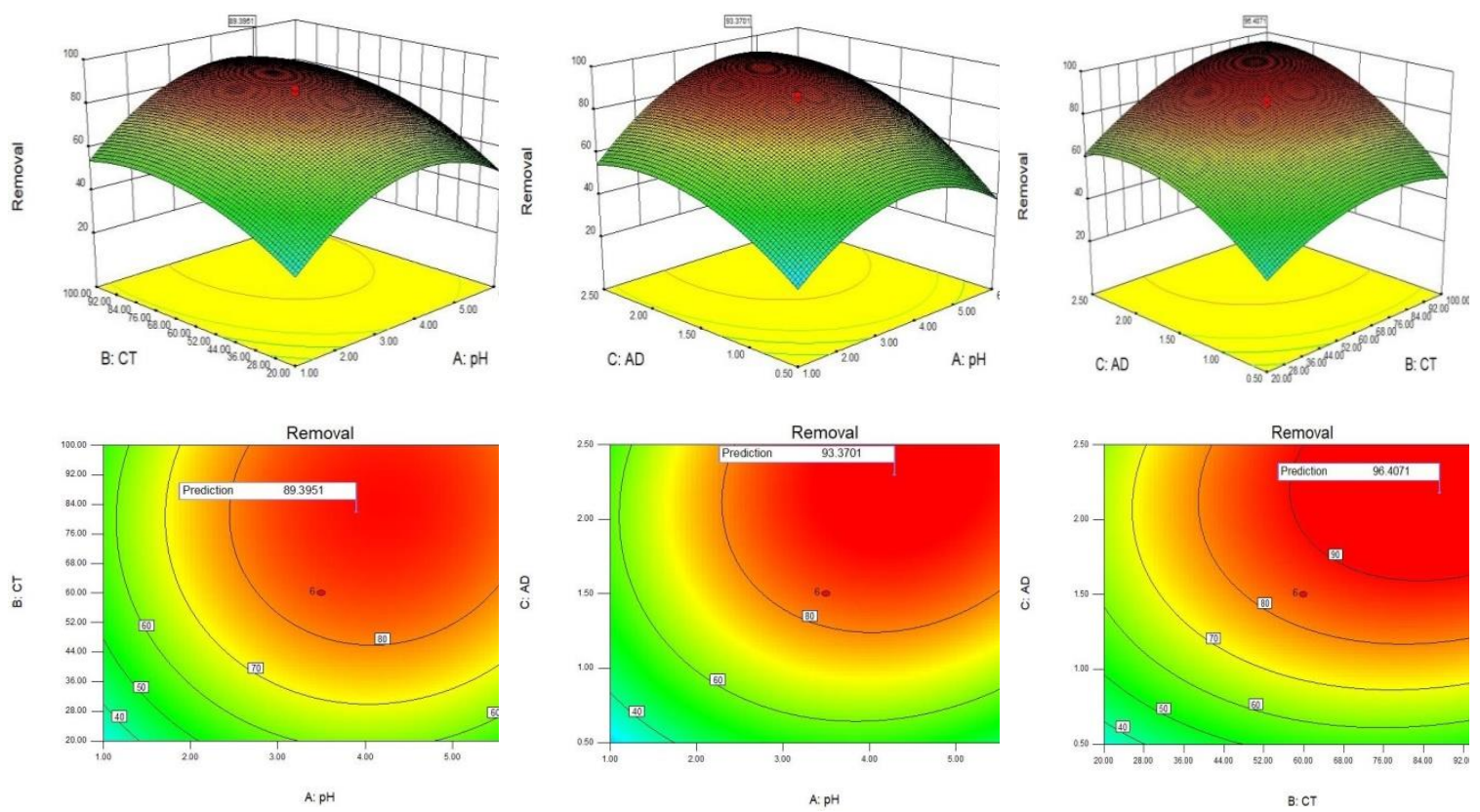

Figure 2 Response surface and contour plot indicate effects of process parameters on Cd (II) removal. 
Figure 2 shows the 3-dimension response surface ( $1^{\text {st }}$ row of Figure 2) and 2-dimensional contour $\left(2^{\text {nd }}\right.$ row of Figure 2) plots to demonstrate the effects of process parameters (i.e., CT, pH, and AD) on Cd (II) removal (Y\%). The maximum removal efficiency of $99.58 \%$ was found at $\mathrm{pH}=4.4758$; $\mathrm{CT}=90.57$ and $\mathrm{AD}=2.3994$ by maintaining initial $\mathrm{Cd}$ concentration of $100 \mathrm{mg} / \mathrm{L}$. The combination and interaction of the $\mathrm{pH}$ effect with $\mathrm{AD}$ and $\mathrm{AD}$ in comparison with $\mathrm{CT}$ were found to be very significant. The $\mathrm{R}^{2}$ values vary from 0 and 1 as this value approaches $\sim 1.0$ implies high precision with the developed model [34,7]. The modified $R^{2}$ (adj $R^{2}$ ) uses the deviation value for the model definition. The adj $R^{2}$ decreases with the increase in the number parameters used for the experiments is agreed by the mathematical equation. Potentially, the adj $R^{2}$ should be neared to $R^{2}$ [32]. The main adaptation among $R^{2}$ and adj $R^{2}$ is the caution that the model may contain an insignificant parameter in the process [34]. The built-in model was established to be excellent, which can be seen from the $\mathrm{R}^{2}$ value. The values of regression coefficients are found as $\mathrm{R}^{2}$ : 0.9969; adj. $\mathrm{R}^{2}$ : 0.9942; pre $\mathrm{R}^{2}$ : 0.9796. Since the $\mathrm{R}^{2}$ values are very good and it can be concluded that that the predicted data reasonably fit the experimental data.

The interaction effect between the AC $(p<0.005)$ and BC $(p<0.005)$, was found to be statistically significant and had a significant effect on the adsorption efficiency of $\mathrm{Cd}$ (II). The $\mathrm{AB}$ is interaction having $p=0.9078$, which is statistically insignificant for the process. The elliptical shapes of the response surface plots signify that there is strong interaction among the process variables. The surface plots have a definite peak it indicates that the optimized condition is well within the selected range of process parameters.

\section{Effect of process variables on adsorption of Cd (II)}

The $\mathrm{pH}$ of the solution is a significant parameter that governs the uptake by Calotropis biomass. The change in $\mathrm{pH}$ affects the ionization level of the metal ion and the surface charge of the adsorbent in the solution. The batch experiments carried at room temperature of $28{ }^{\circ} \mathrm{C}$ using $\mathrm{AD}$ of $2.5 \mathrm{~g}$ at a fixed initial concentration of $\mathrm{Cd}$ (II) of $60 \mathrm{mg} / \mathrm{L}$, and $\mathrm{pH}$ range of 4 to 5 have given optimal range for maximum $\mathrm{Cd}$ (II) removal. The increase in $\mathrm{pH}(2$ - 5) affected the $\mathrm{Cd}$ (II) removal from 13.21 to $90.11 \%$. The maximum removal of $\mathrm{Cd}$ (II) was observed between $\mathrm{pH} 4$ to 5 . The rate of expulsion increases from $\mathrm{pH} 5$ to 6 . At higher $\mathrm{pH}, \mathrm{Cd}$ (II) adsorption forms an anionic complex, which is excluded by negatively charged bio adsorbent. In contrast, at low $\mathrm{pH}$, due to the presence of contrasting ions, the absorption of Cd (II) with high $\mathrm{H}+$ concentrations are significantly reduced [35]. Considering the use of this current treatment study in industrial wastewater, Calotropis Procera root biomass will be suitable at a $\mathrm{pH}$ of 4 to 5 . The most important CT in the adsorption test in Figure 3 shows that with a significant increase in the removal of the Cd (II) ion up to $90 \mathrm{~min}$, a further increase will not be important in the process. The amount of adsorbent varies from $1-5 \mathrm{~g} / \mathrm{L}$, batch tests show 3.5 to $4.5 \mathrm{~g} / \mathrm{L}$ is the major adsorption mechanism for Cd (II). The $\mathrm{Y}$ increased from 22 to $97 \%$ as the $\mathrm{pH}$ of the solution increased from 1 to 4.35 , $\mathrm{Y}$ was increased from 50 to $95 \%$ as the CT increased from 20 to $80 \mathrm{~min}$. Similarly, as the AD increased from 1 to $5 \mathrm{~g}$ the Cd (II) removal was increased from 25 to $95 \%$ and then decreased with higher AD. Figure 3(b) represents the interactive effect of $\mathrm{pH}, \mathrm{CT}$, and $\mathrm{AD}$ for the $\mathrm{Cd}$ (II) removal process. It is observed that high $\mathrm{pH}$ and $\mathrm{AD}$ enable an increase in the removal process. The interaction between process variables of $\mathrm{AC}(p=0.0001, t=6.10), \mathrm{BC}(p=0.0004, t=5.15)$, is statistically significant and has a positive effect on adsorption efficiency $(\%)$ of cadmium, and when combinations of $\mathrm{AB}(t=1.98, p=0.0744)$, had a negligible effect on the adsorption performance of cadmium.
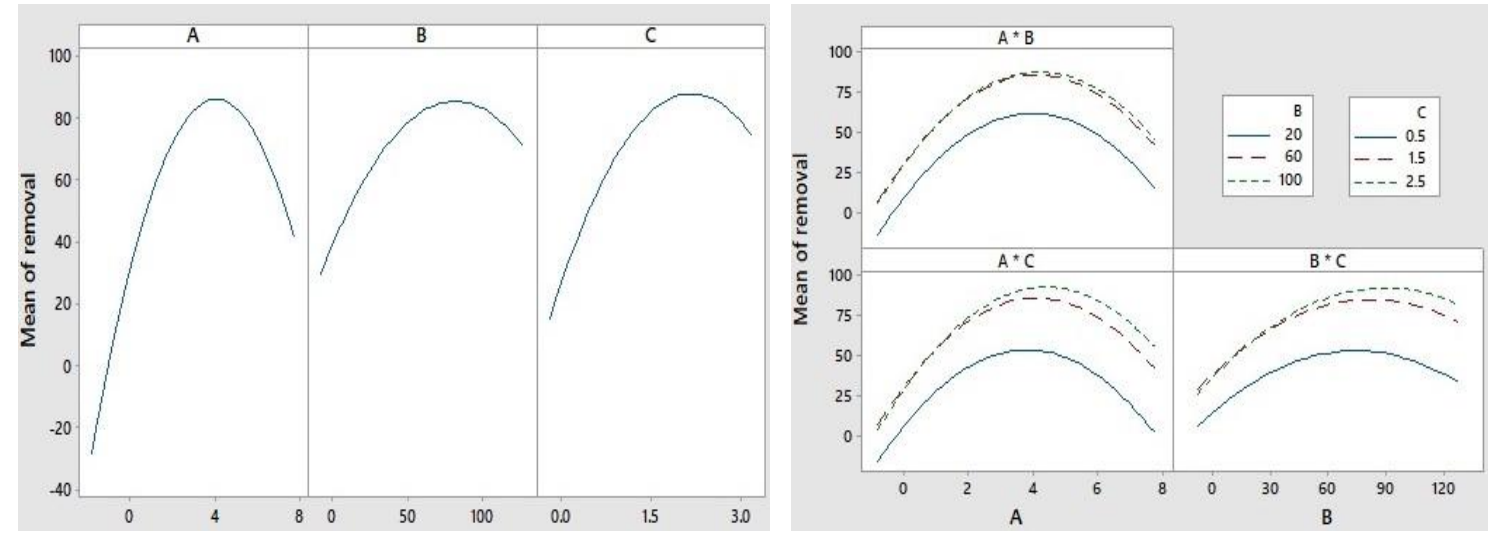

Figure 3 (a) Main effects and (b) interactive effect of process parameters of Cd (II) removal. 


\section{Process optimization and verification of model}

The adsorption of $\mathrm{Cd}$ (II) was modeled using a quadratic equation to make the process a high cadmium removal process. To verify the accuracy of the model, a batch test was used to confirm the highest $\mathrm{Cd}$ (II) removal at the initial concentration of $60 \mathrm{mg} / \mathrm{L}, \mathrm{pH}$ of 4.4.48, $90 \mathrm{~min}$ residence time, and adsorbent dose $2.4 \mathrm{~g}$. The optimum values performed with $98.30 \%$ cadmium removal and were much closer to the predicted value of $99.58 \%$ shown in Figure 4.

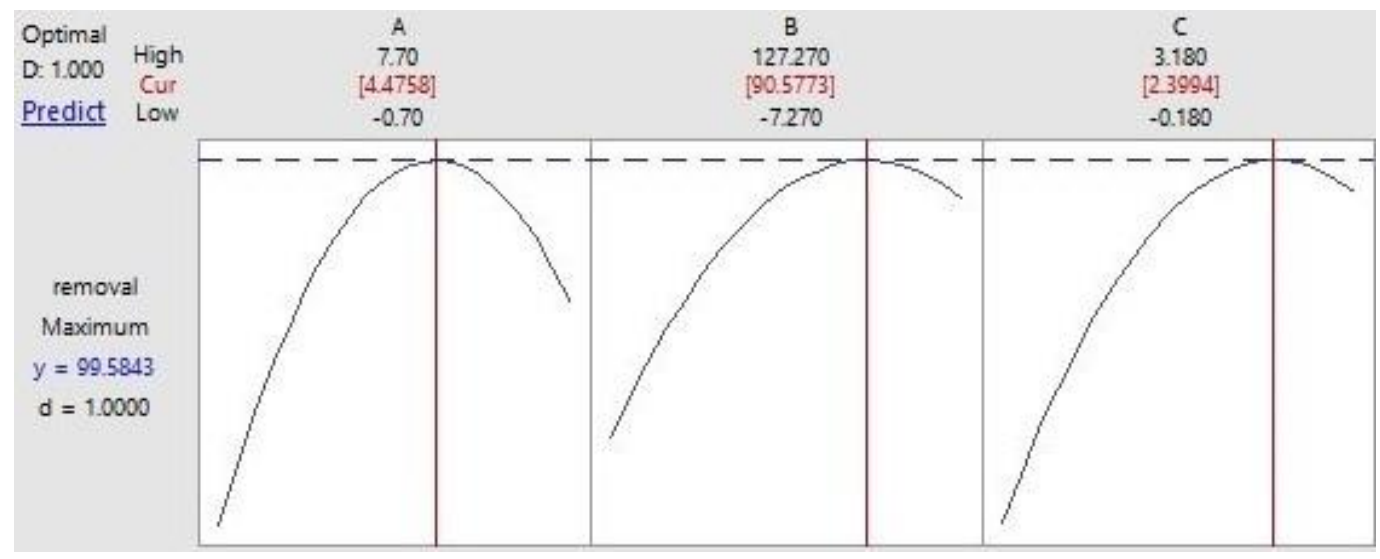

Figure 4 Optimization of maximum Cd (II) removal.

The adsorption of Cd (II) on Calotropis Procera was studied by performing a batch study using 3 process parameters. The process was optimized by the quadratic model using CCD. The prediction of Cd (II) uptake was highly accurate with $\mathrm{R}^{2}=0.9958$. The predicted data and experimental data were compared and the model exhibits a high degree of agreement. The maximum removal percentage was observed at $\mathrm{pH} 4.48$, residence time of $90.58 \mathrm{~min}$, the adsorbent dosage of $2.40 \mathrm{~g}$ at an initial Cd (II) concentration of $60 \mathrm{mg} / \mathrm{L}$. Adsorption was rapid and strongly influenced by $\mathrm{pH}$, Residence time, and adsorbent dose. The adsorption capacity was found to be $\mathrm{pH}$-dependent and the removal of the highest percentage of $\mathrm{Cd}$ (II) was $\mathrm{pH}$ between 4 and 5.

\section{Acknowledgements}

The authors are thankful to the management and the principal, of KLE DR. M. S. Sheshgiri College of Engineering and Technology, Belagavi, for extending facility and support to complete this research work.

\section{References}

[1] FA Olabemiwo, BS Tawabini, F Patel, TA Oyehan, M Khaled and T Laoui. Cadmium removal from contaminated water using polyelectrolyte-coated industrial waste fly ash. Bioinorg. Chem. Appl. 2017; 2017, 1-13.

[2] R Singh, R Chadetrik, R Kumar, K Bishnoi, D Bhatia, A Kumar, NR Bishnoi and N Singh. Biosorption optimization of lead (II), cadmium (II) and copper (II) using response surface methodology and applicability in isotherms and thermodynamics modeling. J. Hazard. Mater. 2010; 174, 623-34.

[3] M Iqbal, N Iqbal, IA Bhatti, N Ahmad and M Zahid. Response surface methodology application in optimization of cadmium adsorption by shoe waste: A good option of waste mitigation by waste. Ecol. Eng. 2016; 88, 265-75.

[4] BIS. Indian standard drinking water specification. Bureau of Indian Standards, New Delhi. 2012, p. 2-3.

[5] JT Li, JW Qiu, XW Wang, Y Zhong, CY Lan and WS Shu. Cadmium contamination in orchard soils and fruit trees and its potential health risk in Guangzhou, China. Environ. Pollut. 2016; 143, 159-65.

[6] TG Ammari, I Al-Labadi, A Tahboub and A Ghrair. Assessment of unmodified wetland bio-waste: Shoots of Cyperus laevigatus, for cadmium adsorption from aqueous solutions. Process Saf. 
Environ. Prot. 2015; 95, 77-85.

[7] M Jain, VK Garg, R Paliwal, K Kadirvelu and S Chaudhry. Optimization of cadmium (II) removal from water using sunflower waste carbon-a statistical approach. Toxin Rev. 2010; 40, 1-10.

[8] UK red list substances, Available at: https://www.legislation.gov.uk/uksi/1991/472/contents/made, accessed June 2020.

[9] SN Hosamane. Removal of arsenic by phytoremediation-a study of two plant spices. Int. J. Eng. Sci. Technol. 2012; 1, 218-24.

[10] L Friberg. Cadmium and the kidney. Environ. Health Perspect. 1984; 54, 1-11.

[11] KD Eum, MS Lee and D Paek. Cadmium in blood and hypertension. Sci. Total Environ. 2008; 407, 147-53.

[12] T Matsukura, C Inaba, EA Weygant, D Kitamura, R Janknecht, H Matsumoto, DP Hyink, S Kashiwada and T Obara. Extracellular vesicles from human bone marrow mesenchymal stem cells repair organ damage caused by cadmium poisoning in a medaka model. Physiol. Rep. 2019; 7 , e14172.

[13] RC Patra, AK Rautray and D Swarup. Oxidative stress in lead and cadmium toxicity and its amelioration. Vet. Med. Int. 2011; 2011, 457327.

[14] Drinking Water Contaminants- Cadmium, Available at: https://www.freedrinkingwater.com/watercontamination/cadmium-contaminants-removal-water.htm, accessed June 2020.

[15] HW Chen, MM Frey, D Clifford, LS McNeill and M Edwards. Arsenic treatment considerations. J. Am. Water Work Assoc. 1999; 91, 74-85.

[16] C Duran, D Ozdes, HT Akcay, H Serencam and M Tufekci. Co (II), and Ni (II) ions in environmental samples by carrier element free co-precipitation method prior to their flame atomic absorption spectrometric determination. Desalination Water Treat. 2015; 53, 390-7.

[17] S Ahmed, S Chughtai and MA Keane. The removal of cadmium and lead from aqueous solution by ion exchange with NaY zeolite. Sep. Purif. Technol. 1998; 13, 57-64.

[18] KS Rao, M Mohapatra, S Anand and P Venkateswarlu. Review on cadmium removal from aqueous solutions. Int. J. Eng. Sci. Technol. 2011; 2, 81-103.

[19] SA Nosier. Removal of cadmium ions from industrial wastewater by cementation. Chem. Biochem. Eng. Q. 2003; 17, 219-24.

[20] KS Rao, M Mohapatra, S Anand and P Venkateswarlu. Review on cadmium removal from aqueous solutions. Int. J. Eng. Sci. Technol. 2010; 2, 81-103.

[21] M Raad, M Srour, A Hijazi, R Hmedeh, Z Damaj, M Hamieh, AA Lami, M Kassir and WE Khatib. Removal of cadmium (II) Ions from waste water by adsorption onto the powder of lebanese anacyclus nigllifolius boiss: A comparative study. Am. J. Phytomed. Clin. Ther. 2017; 5, 11.

[22] VK Gupta, CK Jain, I Ali, M Sharma and VK Saini. Removal of cadmium and nickel from wastewater using bagasse fly ash-a sugar industry waste. Water Res. 2003; 37, 4038-44.

[23] Y Lin, X He, G Han, Q Tian and W Hu. Removal of crystal violet from aqueous solution using powdered mycelial biomass of Ceriporia lacerata P2. Res. J. Environ. Sci. 2011; 23, 2055-62.

[24] D Garai and V Kumar. A Box-Behnken design approach for the production of xylanase by Aspergillus candidus under solid state fermentation and its application in saccharification of agro residues and Parthenium hysterophorus L. Ind. Crop. Prod. 2013; 44, 352-63.

[25] M Khajeh. Application of Box-Behnken design in the optimization of a magnetic nanoparticle procedure for zinc determination in analytical samples by inductively coupled plasma optical emission spectrometry. J. Hazard. Mater. 2009; 172,385-9.

[26] SN Hosamane, K Ghurlhosur and S Bagali. Optimization of lactic acid production from cane sugar molasses. Research Res. J. Pharm. Biol. Chem. Sci. 2008; 4, 872-7.

[27] M Iqbal, N Iqbal, IA Bhatti, N Ahmad and M Zahid. Response surface methodology application in optimization of cadmium adsorption by shoe waste: A good option of waste mitigation by waste. Ecol. Eng. 2016, 8, 265-75.

[28] RH Myers, D Montgomery and CM Anderson-Cook. Response surface methodology: Process and product optimization using designed experiments. John Wiley \& Sons, Inc., New York, 2016.

[29] S Chatterjee, A Kumar, S Basu and S Dutta. Application of response surface methodology for methylene blue dye removal from aqueous solution using low-cost adsorbent. Chem. Eng. J. 2012; 181, 289-99.

[30] S Sen, S Nandi and S Dutta. Application of RSM and ANN for optimization and modeling of biosorption of chromium (VI) using cyanobacterial biomass. Appl. Water Sci. 2018; 8, 148.

[31] M Amini, H Younesi, N Bahramifar, AAZ Lorestani, F Ghorbani, A Daneshi and M Sharifzadeh. Application of response surface methodology for optimization of lead biosorption in an aqueous 
solution by Aspergillus niger. J. Hazard. Mater. 2008; 154, 694-702.

[32] SN Hosamane and GP Desai. Air pollution modelling from meteorological parameters using artificial neural network. In: DJ Hemanth and S Smys (Eds.). computational vision and bio inspired computing. Springer, Cham, 2018, p. 466-75.

[33] W Yong-Fei and W Cheng-Guo. The application of response surface methodology. J. Cent. Univ. For National. (Nat. Sci. Ed.). 2005; 2005, 3.

[34] PK Pandey, Y Verma, S Choubey, M Pandey and K Chandrasekhar. Biosorptive removal of cadmium from contaminated groundwater and industrial effluents. Bioresour. Technol. 2008; 99, 4420-47.

[35] M Jiang, X Jin, X Lu and Z Chen. Adsorption of Pb (II), Cd (II), Ni (II) and Cu (II) onto natural kaolinite clay. Desalination 2010; 252, 33-9. 